\title{
Vanguardias y camuflaje: la guerra como campo de pruebas del arte moderno
}

\section{Avantgarde and camouflage: The war like testing ground of the modern art}

\author{
MAITE MÉNDEZ BAIGES \\ Universidad de Málaga (España)
}

Recibido: 21-IX-2015 Aceptado: 3-X-2015

\section{RESUMEN}

Este artículo estudia la contribución de las primeras vanguardias artísticas del siglo XX a la ideación y puesta en práctica de técnicas de camuflaje militar durante la I Guerra Mundial. Se analizan así el origen cubista de los diseños de camuflaje mimético (o Disruptive pattern Material), el papel desempeñado por los artistas en la ideación de numerosos trompe l'oeil con fines bélicos y la condición del camoufleur como artista-soldado, un sujeto repartido entre lo funcional y lo estético. Todo ello sirve de fundamento para sustentar la tesis de que el contexto bélico sirvió como campo de pruebas de las técnicas, anhelos y formas del arte de las vanguardias históricas.

\author{
PALABRAS CLAVE \\ CAMUFLAJE, CUBISMO, FAUVISMO, ARTE ABSTRACTO
}

\begin{abstract}
This paper discusses the contribution of the early twentieth century avant-garde art to the conception and implementation of military camouflage techniques during the First World War. Some issues are analyzed, such as the cubist origin of mimetic camouflage designs (called Disruptive Pattern Material), the role played by the artists in the ideation of numeorus
\end{abstract}


trompe l'oeil for military purposes and camoufleur condition as an artist - soldier, a subject divided between functionality and aesthetics. All this serves as a foundation to support the thesis that the war context served as a field test for techniques, desires and art forms of the historical vanguards. .

KEYWORDS

CAMOUFLAGE, CUBISM, FAUVISM, ABSTRACT ART

To enlist in the Camouflage Corps

is to embark into mystery.

McCabe, 1918

DURANTE EL PERIODO DE LAS VANGUARDIAS lo siniestro anidó a menudo en la figura del maniquí. Reunía varios requisitos que lo hacían especialmente apto para dar cobijo a esta categoría, como el de ser un objeto en el que lo familiar da la impresión de convertirse en algo inusual o extraño, o el de funcionar como resorte del escalofrío que provocan los seres inanimados por cuya apariencia se habría esperado sin embargo encontrar vida. Ángel González asignó alguna vez la ingente presencia de maniquíes en la pintura del Realismo Mágico y la Metafísica al efecto devastador de la guerra sobre los cuerpos, que había llenado las calles de las ciudades europeas de seres tullidos con miembros artificiales. Lo cierto es que una de las grandes inspiradoras de este motivo, la pintura metafísica del italiano Giorgio de Chirico, no se puebla de maniquíes hasta los años de la I Guerra Mundial, a pesar de remontarse a 1909. Pero los maniquíes no estuvieron presentes solo en la obra artística de posguerra, sino que previamente habían participado con gran eficacia en el conflicto bélico, desempeñando un papel relevante dentro de las técnicas de camuflaje que se pusieron en práctica por primera vez de un modo sistemático precisamente en este contexto, hace ahora exactamente cien años ${ }^{1}$.

Entre las tareas de los integrantes de las recién nacidas unidades de camuflaje figuraba la fabricación de maniquís con los que tender todo tipo de trampas al enemigo. Esos muñecos de apariencia humana, de un naturalismo pasmoso, servían por ejemplo para atraer su atención hacia un cierto lado de la trinchera, de forma que la distrajera del lugar donde el propio ejército llevaba a cabo realmente distintas maniobras y acciones; o como reclamo para atraer el fuego enemigo y así conocer la posición exacta de sus hombres. Hubo un uso de estos maniquís especialmente macabro. Se los hacía pasar por soldados heridos, con la cabeza vendada, y se los arrojaba en tierra de nadie; se llegó a idear incluso un mecanismo mediante cordeles gracias al cual se conseguía que

1 La primera Unidad de camuflaje, creada en el ejército francés, nació en febrero de 1915 y se puso bajo la responsabilidad del pintor Lucien-Victor Guirand de Scevola. 
agitaran el brazo, como pidiendo ayuda a sus compatriotas, que naturalmente eran acribillados en cuanto acudían a socorrer a ese compatriota inesperadamente hecho de madera y trapo. De modo que se podría decir que esos juegos escabrosos con muñecos de apariencia humana a los que tan proclive parecen ser algunos artistas de vanguardia se habían experimentado con anterioridad en el campo de batalla.

Es uno de los muchos ejemplos de la intervención de los artistas de vanguardia, sus técnicas y anhelos, en la I Guerra Mundial a través de lo que se considera una de sus más genuinas creaciones: el «camuflaje total para la guerra total». Este fue el título que le dio Dalí a un texto de los años cuarenta en el que aseguraba que el camuflaje de la Primera Guerra Mundial había sido cubista y picassiano, y que el de la Segunda era surrealista y daliniano (Dalí 1942, 223). Lo cierto es que el camuflaje permitirá que se experimenten modos y poéticas vanguardistas en uno de los ámbitos aparentemente más alejados de lo artístico, el de la guerra. Pues se revelará como uno de los mejores vehículos para sacarle todo el partido posible a esa secular habilidad de los artistas consistente en sembrar la confusión entre realidad y ficción (los maniquís eran una forma más de hacer pasar la mentira por verdad), y como un óptimo campo de experimentación de técnicas y poéticas vanguardistas, entre las que las del extrañamiento ocupan un lugar destacado. No solo eso, el campo de batalla parece ser un lugar idóneo para poner a prueba muchos de los principios sobre los que descansa esa nueva noción de lo artístico que proponen las vanguardias europeas de las primeras décadas del siglo XX. Ya en su momento los titulares de periódicos y revistas de la época llamaban la atención sobre las semejanzas entre el arte más avanzado y las obras del camuflaje mimético (utilizadas en el ejército de tierra con el nombre técnico de Disruptive Pattern Material) y de la Dazzle Painting (la técnica empleada en el ámbito naval): «Barcos como cuadros cubistas», titulaba el Daily Chronichle del 10 de diciembre de 1919, o «Arte cubista como defensa de los mares», rezaba otro del Manchester Guardian en diciembre de ese mismo año.

\section{AVIONES, BARCOS Y ARLEQUINES}

En la I Guerra Mundial, como ha explicado Massimo Scolari $(1989,61)$, la fuerza militar se vio impelida a no dejar rastro en la fotografía, a aplanarse en el fango de las trincheras, desfigurar las propias formas o desaparecer grotescamente en el paisaje. Y a ello se aplicaron especialmente los artistas, que presentaron sus propuestas sobre la invisibilidad y el engaño basándose en lo que constituía la clave de su nuevo lenguaje: la sustitución del disimulo propio del mimetismo naturalista por el engaño de la simulación. Las habilidades supuestamente deformantes de la pintura cubista, fauvista, vorticista o abstracta parecían especialmente aptas para prestar servicio a estos fines. 
Como hemos avanzado, quedó en manos de los artistas la ideación y adopción sistemática de las técnicas militares de camuflaje. Esa guerra, que acabó con todo un mundo e instauró otro, también supuso, durante un plazo de tiempo limitado y solo durante ese tiempo, una oportunidad para el establecimiento de una firme alianza entre lo artístico y lo militar, basada en la convicción de que el camuflaje es un arte; una convicción que, tengámoslo en cuenta, podría haber sido de otro modo. Según $\operatorname{Roskam}(1989,24)$ el camuflaje siempre se ha considerado más un tipo de improvisación visual, y por lo tanto algo propio del terreno artístico, que un experimento científico, técnico o militar. Habría dado lugar, así, a una alianza improbable e inesperada, ya que suponía la unión de dos temperamentos por lo común considerados antagónicos, el del artista frente al del militar. Los artistas no parecían en principio hombres especialmente destinados al servicio militar o a ocupar un lugar estratégico en el combate. En 1920, el periodista francés Jean de Pierrefue escribía que si a un pintor de la guerra anterior, la francoprusiana de 1870, uno de esos pintores que por entonces había tirado sus inútiles pinceles para empuñar las armas, le hubieran dicho que 44 años después se pediría a sus sucesores que se desprendieran de los rifles para empuñar los pinceles, se habría quedado atónito (Pierrefue 1920, 28).

Y así fue. De este modo, la nueva ciencia del enmascaramiento militar se llegó a considerar un producto de la guerra moderna, pero «también un ismo artístico» (Scolari 1989, 63). De hecho, el camuflaje reúne dos características que a veces se han considerado incompatibles, la de ser práctico y estético al mismo tiempo, cumpliendo ese papel doble o ambiguo sobre el que pivotarían los debates de prácticamente todos los movimientos de vanguardia de las primeras décadas del siglo. No debe llamar así la atención el hecho de que la primera idea del camuflaje como forma de defensa de la artillería frente a la observación aérea proceda de un pintor vanguardista, y nos referimos nada menos que a Picasso: «Voy a darte una buena idea para la artillería, le escribía en 1915 a su amigo Apollinaire, que se encontraba en el frente. La artillería solo puede ser avistada por los aeroplanos; como los cañones, incluso los pintados de gris, conservan la forma, se deberían pintar de colores vivos y a trozos rojos amarillo verde azul blanco en arlequín» (Picasso/Apollinaire 2000, 139).Y, en efecto, durante la I Guerra Mundial las fuerzas aéreas servían fundamentalmente para vigilar los movimientos y equipamiento del ejército enemigo. Picasso le estaba recomendando al poeta rebajar la visibilidad de la artillería ante esos ojos del cielo por medio de la desfiguración de la forma de los cañones, algo que era posible lograr aplicando el mismo procedimiento que venía usando el cubismo para representar los objetos y figuras sobre el plano pictórico, descomponiéndolos en facetas o planos de colores. Invisibilidad, desestructuración de la forma o ambas al mismo tiempo son asimismo las finalidades que se buscan en las 
prácticas de camuflaje, o decepción, para confundir al enemigo acerca de lo que está observando. El término decepción es el término técnico usado para el camuflaje en el ámbito militar, y recoge mejor que este último el verdadero objetivo que persigue, el del engaño.

La confluencia de cubismo y camuflaje no pasó desapercibida a los críticos de arte más perspicaces del momento. André Salmon, gran amigo de Picasso, afirmaba en 1920 que el camuflaje se lo debía todo al cubismo, y llegó a considerarla forma de camuflar típica de la marina, la Dazzle Painting, como $« i \mathrm{La}$ obra maestra del género!»; a ello añadía esta explicación:

Todo el principio reposa en la teoría de los planos y de los volúmenes, pero aplicados de tal modo - con un rigor en sentido contrario, diría- que es imposible saber cuál es la cara que el navío le presenta al ojo. Todos los combatientes que saben ver, os dirán que de la primera a la segunda línea, donde los planos están más sobriamente confundidos, todo tiene los colores elegidos, reservados, tan graves, que constituyen la paleta de Picasso o de Georges Braque. (Salmon 1920, 162).

\section{EL DEBATE SOBRE REALISMO Y ABSTRACCIÓN EN EL CONTEXTO BÉLICO}

Confundir al observador sobre lo que está viendo, engañar al ojo y al espíritu (trompe-l'oeil y trompe-l'esprit), son habilidades genuinas de los pintores, ora celebradas ora vituperadas desde los griegos. Cuántas veces no se detiene Vasari con deleite a narrar las proezas de aquellos pintores renacentistas que lograban que lo representado en sus obras se confundiera con la realidad. Pero la confluencia de arte y camuflaje va más allá de estas virtudes seculares de los pintores, e implica la ideación y puesta en práctica de procedimientos con claras resonancias vanguardistas, tanto desde el punto de vista formal como desde el conceptual.

Para confundir las observaciones del enemigo los artistas soldados se emplearon a fondo en la representación de falsas trincheras, baterías, pistas o senderos que servían la mayoría de las veces para ocultar los verdaderos. El campo de batalla se convirtió así en un inmenso trampantojo. Curiosamente, aunque parte del mismo consistía en técnicas ilusionistas, para otras se desestimó cualquier tipo de naturalismo, poniendo en práctica, como hemos dicho, procedimientos inspirados en el cubismo y la abstracción. Delouche explica que la pintura de camuflaje se dirigió espontáneamente al cubismo porque se encontraba enfrentada a una ecuación plástica similar, la de la inscripción total de un objeto en su medio ambiente: el paisaje para una, el espacio plano del lienzo para el otro (Delouche 1998, 60). Así, la ilegibilidad del motivo a la que había conducido la exploración profunda del objeto en los cubistas coincidía con la invisibilidad del objeto perseguida por los camoufleurs. Enseguida se 
llegó a la conclusión de que recrear la realidad de forma naturalista no habría funcionado, mientras que el resquebrajamiento cubista de la realidad visual sí resultaba efectivo. A efectos prácticos, el «realismo» no resultaba tan eficaz, o tan real, mientras que la aplicación de los principios de la pintura cubista era capaz de lograr que aquello que se intentaba escamotear a la vigilancia enemiga adquiriese efectivamente el aspecto de lo real, hasta confundirse con él. La operación entraña aún otra paradoja: para los camoufleurs la teoría cubista era importante porque el objetivo último del camuflaje era disfrazar o impedir una lectura coherente del objeto, aunque el propio artista cubista concibiera que su obra era todo lo contrario, una forma de ofrecer más información sobre el mundo visual que la que solía ofrecer la tradición previa, basada en la utilización de un único punto de vista.

En 1952, otro de los más célebres críticos del cubismo, Jean Paulhan, reiteraba que el camuflaje de guerra había sido efectivamente obra de los cubistas, para subrayar que cuando al comandante de la primera Sección de camuflaje francesa, el pintor Guirand de Scevola, se le reprochó por razones políticas el haber apelado en momentos tan críticos a «pintores, digamos, germanófilos y absurdos; de hecho, a cubistas» (Paulhan 1952, 133), justificó de este modo su elección: «Lo que pintan los cubistas no se parece en nada a su modelo: estaban pues predestinados para pintar cañones que nadie tomaría por cañones» (Guirand de Scevola 1950, 720). Es evidente, por tanto, que Guirand de Scevola había sopesado las ventajas del carácter antinaturalista, o aparentemente no mimético «respecto a su modelo», del cubismo. Ahora bien, cabría preguntarse si la pintura de camuflaje sirve efectivamente para que lo fingido no se parezca a nada, o, por el contrario, para que se parezca a la realidad misma hasta el punto de confundirse con ella, ya que el objeto último del camuflaje terrestre es lograr la entera mimetización con el entorno. Y teniendo en cuenta la singular pareja que forman a este respecto cubismo y camuflaje, estas preguntas nos conducirían sin duda al espinoso problema del debate aún abierto a día de hoy sobre abstracción y representación en el cubismo. Porque, si los principios del cubismo se pudieron aplicar a la pintura de camuflaje ifue debido a sus virtudes miméticas, o a su capacidad de abstracción? La afirmación de Guirand de Scevola que acabamos de transcribir le valió que Paulhan lo considerase con evidente menosprecio un «crítico de arte dominguero» que siente por el cubismo un «curioso desprecio». Porque a juicio de Paulhan, aunque al fundador del camuflaje francés le hubieran salido bien las cosas cuando decidió enrolar a cubistas en su sección, su decisión la habían motivado razones equivocadas, puesto que en realidad no había entendido lo que era el cubismo. Paulhan no negaba el papel que había representado el cubismo en la labor de los camoufleurs, pero la atribuía a razones enteramente distintas a las de Guirand de Scevola, en concreto, al carácter «realista» de la pintura cubista: 
Hubo un tiempo en el que se quiso cambiar el aspecto de las barracas, los cañones, los automóviles. Se quería que parecieran árboles, piedras. Pues bien, se tuvo que apelar a Braque y a Picasso. El camuflaje de guerra fue obra de los cubistas: si se quiere, era también su revancha. Los únicos cuadros a los que la opinión pública reprochaba no parecerse a nada, resultaban ser, en el momento del peligro, los únicos que podían parecerse a todo [...] Y el aviador que dudaba del bosque de las Ardennes o de la Beauce, ya no vacilaba ante un cañón retocado por Braque: era finalmente un árbol verdadero, una llanura plana, hojas muertas que estaban bien muertas. Ya sé por qué una tela tan grande como un pañuelo me producía la extraña impresión de que al pintor no se le había olvidado nada. Y es que la tela podía extenderse y cubrir camiones, un campo, la Francia entera (Paulhan 1952, 25-27).

Todo ello pondría de manifiesto, en última instancia, hasta qué punto el nuevo lenguaje artístico que estaban articulando los movimientos de vanguardia desde finales del siglo XIX, basado en el repudio a la «falsedad» naturalista, y en la concepción de una forma de representar la realidad que coincidía con la de crearla o construirla, no pretendía en última instancia un divorcio de lo real.

Ahora bien, no fueron exactamente Braque ni Picasso los que «retocaron» directamente con sus brochas y pinceles esos cañones, sino los cubistas de Salón, algunos miembros del Blaue Reiter alemán y pintores pertenecientes al Vorticismo británico, entre otros.

\section{LOS ARTISTAS DE VANGUARDIA EN EL PAPEL DE CAMOUFLEURS}

En la sección francesa de camuflaje se enroló a artistas representantes de las tendencias más arriesgadas de los salones parisinos recientes: fauves como Othon Friesz, Charles Camoin y quizá Jean Puy; y cubistas de Salón como André Mare, que ha dejado una inestimable colección de Carnets de guerre, Roger de la Fresnaye, André Lhote, Marcoussis, Herbin y uno de los hermanos de Duchamp, Jacques Villon. También está documentada la participación de otros pintores afines a estas tendencias, como Dunoyer de Segonzac, Louis Boussingault o Charles Dufresne. El ejército alemán, por su parte, se benefició de las habilidades de un pintor abstracto como Franz Marc, mientras el británico contaba entre sus filas al vorticista Edward Wadsworth, que se especializó en barcos dazzle.

En un curioso fenómeno de contaminación recíproca entre cubismo y camuflaje, muchos de los pintores movilizados fueron progresiva o esporádicamente adoptando, durante los años de la guerra, un lenguaje cubista cada vez más radical en su propia obra. Así lo muestran especialmente los cuadernos de guerra de Mare a los que me he referido antes (estudiados por Claire I. R. O’Mahony 2010, 11-35), en el que los motivos representados van perdiendo 
consistencia naturalista hasta alcanzar la caligrafía sígnica y aplanada propia de las tendencias más vanguardistas del momento. Como Mare, también Léger, Villon, Dufresne, Roger de la Fresnaye o Segonzac considerarán que el estilo cubista era lo más apropiado para dar cuenta de la imaginería de la guerra, una experiencia moderna que exigía un tratamiento moderno. Esto parece haber sido una convicción generalizada en los artistas del momento y tuvo como efecto la radicalización de sus creaciones, en justa correspondencia con el paisaje visual de la guerra: la fragmentación o alboroto visual cubista parecía mantener una perfecta consonancia con el escenario de la guerra, tan fragmentario y caótico que no solo resultaba difícil de leer, sino que convertía a los seres humanos y su entorno en formas equivalentes, a veces indistinguibles unas de otras. Como ocurría en los cuadros cubistas. Ya lo hemos dicho, era la propia realidad la que se dedicaba al juego macabro de la indistinción del todo. Esa indistinción que años más tarde analizará Caillois en su célebre artículo sobre «Mimetismo y psicatesnia legendaria» para llegar a la conclusión de que aquellos individuos cuya identidad se diluye en la de su propio entorno, estarían evocando una forma patológica de mimetismo: la fusión de espacio y cuerpo evocan ausencia de autonomía e identidad, propicias para la perdición (Caillois 1935, 5).

En relación con esta patología, resulta curioso constatar el efecto que podrían haber creado entre la tropa algunos los primeros uniformes de camuflaje $D P M$ conocidos, diseñados por el pintor Eugène Corbin ${ }^{2}$ en el transcurso de la I Guerra Mundial, y que tuvieron una condición meramente experimental, sin llegar a producirse en serie. Los escasos uniformes miméticos que se probaron en ese momento abarcan un abanico que va de lo espectral a lo absurdo y grotesco. Aparte de los impedimentos prácticos que pudieron desaconsejar su adopción masiva, hay que tener en cuenta que esos diseños de Corbin contaban probablemente con un grave inconveniente, de naturaleza más simbólica que funcional. En caso de haberse adoptado, habrían supuesto la sustitución de los rutilantes atuendos rojos y azules del uniforme de antaño, símbolos inequívocos de un guerrero que se muestra orgulloso de serlo, que desafía cara a cara al enemigo, por una especie de traje amorfo de verdes y castaños deslavados que, aparte de esconder al soldado ante el enemigo, convertían a la figura humana en algo irreconocible capaz de provocar escalofríos. Porque seguramente habrían sido eficaces en su tarea de que el soldado no se destacara sobre el paisaje, pero de rebote, apenas permitían que se le reconociera como un ser humano. Recuerdan demasiado a esas figuras enfangadas y de aspecto desaliñado, afligidas e incapaces de entender nada de lo que sucede a su alrededor, que nos muestran

2 En el debate acerca de la paternidad del camuflaje militar durante la I Guerra Mundial, hay algunos partidarios de atribuirlo a Eugène Corbin, pintor aficionado, y Luis Guinhot, pintor y decorador de la Escuela de Nancy. Véanse: Nouveau 75, 42-25; Corider, 2014; y Peccatte 2015, 6. 
a menudo las fotografías de soldados en las trincheras durante la Gran Guerra, una imagen de desamparo que deja poco margen a la retórica triunfalista o heroica de la guerra. Los uniformes de Corbin, al suprimir ese régimen de máxima visibilidad propio de los uniformes militares, asentado en siglos de tradición guerrera, evocan a su pesar a ese soldado de infantería que aparece descrito en 1918 en La Psychologie du soldat: «el ser social de antaño apenas era reconocible en este soldado desgreñado, cubierto del barro y la porquería de las trincheras, atormentado por los piojos» (Huot y Vouvenel 1918, 116). Una imagen, además, que atestiguaría que era el propio paisaje bélico el que se encargaba por sí solo de borrar, desfigurar y camuflar a los seres humanos. Como también escribe Scolari:

El escenario de la guerra del siglo XX se reveló como una fangosa grisaille desfigurada por los obuses, poco atractiva para el pintor en plein air, más cercana, ciertamente, a los «descuartizamientos» del cubismo. La bella definición del soldado alemán Paul Klee-«extraer la forma de la fangosidad de lo real»-se convirtió en una angustiosa consigna para los artistas del camuflaje (Scolari 1989, 63).

Antes de abandonar este epígrafe, reparemos por un momento en las condiciones de soldados camoufleurs que adoptaron muchos artistas de vanguardia; se trata de un soldado artista, un híbrido inédito en el campo de batalla, alguien con responsabilidades militares pero que al fin y al cabo seguía siendo un artista que, además, gozaba de un estatuto especial en el ejército. Hay que tener en cuenta que a principios del siglo XX el artista seguía siendo visto bajo la doble perspectiva ilustrada y romántica: un ser creativo especial, dedicado a un campo extraño ajeno a la racionalidad de los fines que rige para el resto de la sociedad, consagrado a aquello que según la tradición kantiana cae en el campo del juicio desinteresado, lo opuesto a la vida práctica movida por el interés que es vital para la existencia y el buen funcionamiento de la sociedad capitalista. El artista de vanguardia, si bien en un contexto plagado de contradicciones y debates, era hasta el momento (antes de la irrupción de las vanguardias abstractas) un firme defensor de la autonomía del arte, un guardián celoso de la frontera entre arte y praxis vital. Como camoufleur, se le requería sin embargo ponerse de nuevo al servicio de lo práctico, incluso de una praxis mortal. Los estudios de E. L. Kahn (1984) y de Delouche (1993 y 2004) describen la condición, carácter y aspecto de los hombres que conformaban las secciones de camuflaje: mantenían un estatuto especial, que los equiparaba más a los oficiales que al soldado raso. Vestían de un modo especial, cultivando una especie de dandysmo belle époque. Por mucho que sus creaciones tuvieran un fin muy específico, el resto de la tropa consideraba que se dedicaban a caprichos artísticos, «bariolages fantaisiste»; los consideraban, en fin, unos pintamonas (Delouche 2004, p. 293). Pertenecer a la unidad de camoufleurs era tenido por 
un «bon filon» («chollazo») (Delouche 1993, 129) y se han conservado cartas y documentos de pintores como Léger, Delaunay o Segonzac que así lo avalan: por ellos sabemos que no parecía ser inusual el que los artistas accedieran a esta sección moviendo los hilos necesarios de un buen enchufe.

\section{GUERRA Y ARTE: EL IMPERIO DEL SIMULACRO}

El camuflaje al que nos hemos referido hasta ahora es el que en la jerga técnica se conoce como camuflaje estático, de naturaleza pictórica. Pero las actividades de los camoufleurs abarcaban mucho más, lo que en esa misma jerga se conoce como camuflaje dinámico. En estas tareas se todo tipo de artistas: arquitectos, decoradores, escenógrafos, escultores, diseñadores, etc. El camuflaje puso a prueba toda su inventiva, y la superaron con creces. Recordemos que el camuflaje es básicamente engaño, y por eso convirtió a esos artistas en algo que quizá ya eran desde el principio, un poderoso ejército de falsarios que transformó la guerra, su paisaje y su conducta, como ya hemos apuntado, en un gran trompe-l'oeil, en una trampa a gran escala (Delouche 2004, 295).

De hecho, en el momento en el que los militares tuvieron que tomarse en serio ese engaño en el que, como ya escribió Sunzi hace unos 2.300 años, consiste básicamente el arte de la guerra, se recurrió a esos experimentados urdidores de artimañas y estafas que son los artistas. En el repertorio de falsedades ideadas por los artistas del camuflaje figura una colección de objetos que bien podrían conformar una espléndida cámara de la maravillas. Esa es exactamente la impresión que producen los objetos que vemos acumulados en las fotografías de talleres de camuflaje que aún se conservan. En ellas podemos apreciar tanques falsos, fabricados con madera, que además se ven cubiertos de pintura mimética, Disruptive Pattern Material, para parecer aún más auténticos, aunque ello los convierta en doblemente falsos: en algunas fotografías se puede ver la divertida instantánea de soldados que transportan por los aires estos tanques de juguete. También figuran en esta colección árboles falsos que servían para ocultar puestos de observación. La construcción de estos árboles comportó el desarrollo de una técnica de lo más sofisticada, en la que al parecer los franceses llegaron a mostrar una gran maestría. Se empezaba por hacer una copia dibujada desde varios puntos de vista de un árbol real, una representación lo más fiel posible. Estos croquis servían para que se reprodujera en el taller, con distintos materiales, un árbol idéntico al original, pero hueco, de modo que pudiera albergar a uno o varios hombres. Se procedía entonces a transportarlo al lugar en el que se encontraba el árbol real. Se cavaba una zanja y se introducía y se dejaba descansar en ella el árbol falso, hasta el momento de ser alzado, y de ser derribado el real, en una operación de cambiazo en toda regla. Entre los objetos de nuestra cámara de maravillas del camuflaje también se cuentan telones que reproducían fielmente el paisaje, a través de técnicas, 
ahora sí, naturalistas, mediante perspectivas fingidas capaces de sembrar la confusión entre la tropa enemiga. Y en esta lista hemos de mencionar también, naturalmente, esos maniquís a los que nos referíamos al principio.

Todo esto, unido a la extravagancia de los diseños miméticos y dazzle suscitaba todo tipo de sospechas, tanto entre la población civil como entre la militar, sobre todo entre aquellos que ya de antemano no simpatizaban demasiado ni con la pintura moderna ni con sus ejecutantes. Y es que el camuflaje reunía el imperio de lo falso y el engaño con el de lo macabro y lo trágico que entraña ya de por sí una guerra. Ya lo dije antes, los uniformes experimentales, por ejemplo, recordaban demasiado la deshumanización y destrucción del individuo que comportaba la civilización industrial y esa su magnífica manifestación que fue la guerra del 14. La propia palabra, camouflage, se había utilizado hasta el momento en el slang francés de los malhechores como sinónimo de timo.

Un cúmulo de factores alimentaban estos recelos, y, entre otros, la asimilación que la mayoría de la población hacía del camuflaje al cubismo, o, de una forma difusa, a la pintura moderna, porque la sospechosa era esta, al menos desde que el nacionalismo francés había conseguido fijar los términos en los que se debía evaluar el arte moderno en general. Desde hacía tiempo se difundía que el cubismo era un arte no francés, incluso antifrancés o antipatriótico, un producto muniqués, o directamente boche. Picasso se había permitido tomarse a broma estas acusaciones en una vista de la ciudad de París, ya en 1912. Desde ese año, la paranoia nacionalista había ido aumentando, y es muy posible que esta sea la razón de que los documentos militares guarden silencio acerca de la influencia del cubismo en el camuflaje; al menos, no se explayan tanto como las revistas generalistas. En el frente estos vanguardistas camoufleurs se mostraban terriblemente airados por los insultos, al tiempo que, como habíamos dicho, su arte se iba cubistizando, o sea, anclando a la vanguardia, por momentos. La mentalidad nacionalista exacerbada hacía inaceptable el reconocimiento de cualquier tipo de deuda con un arte que se consideraba oriundo de tierras enemigas, y que, todo sea dicho, tampoco contaba con las simpatías de las mentalidades más convencionales desde su aparición en los salones parisinos. Al volver del frente, asegura Kahn, los camoufleurs se dieron cuenta de lo arriesgado que había sido convertirse en artistas de vanguardia en armas, y lo solos que estaban, con su mentalidad propia de tiempos de guerra; percibieron, en definitiva, lo peligroso que había sido aceptar el matrimonio entre arte y camuflaje (Kahn 1984, 141 y ss.).

\section{EL EFECTO DE UN KANDINSKY A 2.000 METROS DE ALTURA}

Lo cierto es que ese matrimonio tiene que ver con otros asuntos que afectan directamente a nuestra noción de la vanguardia o la modernidad artística. Pone de manifiesto, para empezar, la existencia de una profunda complicidad 
entre el camuflaje y el arte las vanguardias en un sentido amplio. Nos alerta sobre la presencia de un cúmulo de afinidades cuyas repercusiones en nuestra noción actual de lo que fueron y significaron las vanguardias artísticas del siglo XX no pueden ni deben pasarse por alto. Tiene razón Elizabeth Louis Kahn al afirmar que el camoufleur y su arte son algo que ofrece potencial para una radical redefinición del arte y del artista en la sociedad occidental $(1984,10)$. $\mathrm{Y}$ es que sus afinidades no son epidérmicas, sino fundamentales.

En primer lugar, no sería aventurado afirmar que la guerra fue el primer escenario que ofreció las condiciones favorables para la puesta en práctica de premisas o consignas vanguardistas. Es como si en la vinculación entre arte, guerra y camuflaje se hubieran estado cumpliendo anticipadamente (o quizá ensayado) algunos de los anhelos que propugnarán las vanguardias, sobre todo esos movimientos surgidos durante la guerra, como una alternativa a su violencia y su caos, por paradójico que pueda parecer.

No deja de sorprender que la así considerada "pintura pura» tuviera una aplicación práctica inmediata en el campo de batalla a partir de 1915, dotando así de un nuevo sentido al binomio arte-praxis vital que asociamos habitualmente con las vanguardias, pues estaría suponiendo la aplicación práctica y la extensión al entorno de procedimientos pictóricos vanguardistas. Algunos de los artistas abstractos implicados en tareas de camuflaje, como Franz Marc, no ocultaron su desconcierto ante esa vertiente pragmática, y militar, a la que se veía abocado el arte abstracto, una lenguaje que tanto él como Kandinsky, su compañero de filas en el Blaue Reiter, apreciaban especialmente por su inutilidad, esto es, por su autonomía, por su alejamiento del imperativo de la racionalidad de los fines. En una de las cartas enviadas desde el frente, Marc se explayaba sobre su trabajo de camuflaje de tiendas de campaña militares y confesaba sentir curiosidad por el efecto que provocarían sus kandinskys a 2000 metros de altura (Marc 1996, 165-166).Y también Braque se sentía atraído por la confluencia de arte y vida que entrañaba este tipo de tareas: «Me gustaría escribir sobre la importancia del arte en la vida, sobre sus influencias. Uno no puede imaginar el lugar que ocupa, y su efecto en cosas que parecen remotas de la pintura [...] En 1914, me alegró percibir que el ejército había usado los principios de mi pintura cubista para el camuflaje» (Braque en declaraciones a Liberman 1960, 43).

El camuflaje alemán es quizá el que guarda un más estrecho parecido con composiciones abstractas del momento. Se puede percibir en los diseños que decoraban los aviones, o los cascos de los soldados, con formas más o menos romboidales de colores planos separadas por gruesas líneas negras. En otras ocasiones presentan un asombroso parecido con los diseños de la artista Sonia Delaunay. Y puede que no se trate de un parecido anecdótico, si tenemos en cuenta que tanto los diseños abstractos del camuflaje de la I Guerra Mundial 
como los de una artista cual Sonia Delaunay habrían supuesto situar la pintura vanguardista fuera de sus ámbitos tradicionales, en la calle, por así decir, al tiempo que conceder un carácter práctico o útil al lenguaje abstracto. El camuflaje fue, como sugiere Javier Arnaldo (2009), la forma de divulgación, a escala planetaria, de la pintura abstracta.

Pero es que el maridaje de camuflaje y arte vanguardista no solo propició la puesta del arte puro al servicio de fines utilitarios. También habría supuesto la posibilidad de encauzar muchos otros principios del arte de vanguardia. Por ejemplo, poner en práctica la idea de un arte como tarea colectiva, no íntima o atada a la noción tradicional de autor, no necesariamente vinculada al individuo. El artista pompier trabajó en la guerra mano a mano con el artista moderno, según los ideales de la comunidad de artistas propugnada con anterioridad por un Morris o un Ruskin y que la Bauhaus retomará con entusiasmo. Un artículo de la época, The Art World, fechado en enero de 1918 menciona la colaboración en las tareas del camuflaje de pintores, ilustradores, escultores, arquitectos, ingenieros, escenógrafos, pintores de casas, carpinteros, diseñadores, fabricantes de maquetas, maquilladores, constructores de decorados para el cine, etc. (McCabe 1918, 313). Asimismo el arte del camuflaje respondía a ese otro anhelo de las vanguardias consistente en la no distinción y no jerarquización entre artes decorativas y bellas artes: lo producido es fruto de una integración de artes y oficios diversos. Supuso además la posibilidad de un arte realizado fuera de los espacios especializados, de eso que en el vocabulario vanguardista llamamos un arte en la calle, que es precisamente lo que perseguía esa modernidad radical que se encaminó hacia el ámbito del diseño. Y, por último, el camuflaje habría implicado el logro de un arte efímero, sin aspiración alguna a la eternidad.

Como ha expresado Roskam $(1989,25)$, hay algo tragicómico en que el adagio de futuristas y constructivistas de acabar con la pintura de caballete fuera llevado a la práctica en los campos de batalla de una guerra devastadora y moderna. Ignoro si esto nos conduciría a conclusiones muy alentadoras sobre la noción artística de las vanguardias, pero sí se puede asegurar que todo ello, unido a la radical y deliberada confusión entre ficción y realidad, figuraba en los programas de las vanguardias artísticas del siglo XX, sobre todo de esas que nacieron durante la guerra, y en contra de la guerra. 


\section{REFERENCIAS BIBLIOGRÁFICAS}

ARNALDO, J. 2009: ;1914! La vanguardia y la Gran Guerra. Madrid: Museo ThyssenBornemisza.

CAILloIs, R. 1935: «Mimétisme et psycasthénie légendaire», en Minotaure, n. 7, pp. 5-10.

CORDIER, M. 2014: «Camouflage: mise au point», en Revue indépendante, n. 340, 23 mars.

DALí, S. 1942/1994: «Camuflaje total para la guerra total», en ¿Por qué se ataca a la Gioconda? Madrid: Siruela.

DELOUCHE, D. 1993: «Cubisme et camouflage», en Guerres Mondiales et conflits contemporains, $\mathrm{n}^{\mathrm{o}}$ 171, pp. 123-137.

DELouche, D. 2004: «Camouflage», en Encyclopédie de la Grande Guerre, 1914-18. París: Bayard, pp. 287-296.

DERAIN, A. 1994: Lettres à Vlaminck, suivies de la correspondance de guerre, texte établi et présenté par Philippe Dagen. París: Flammarion.

DUNOYER DE SEGONZAC 1917: Notes prises au front. París: Société Littéraire de France. GIMPEL, René 1963: Journal d'un collectionneur marchand de tableaux. Paris: CalmannLévy.

GUIRAND DE SCEVOLA, L.-V. 1950: «Souvenirs du camouflage (1914-1918)», en Revue des deux mondes, n. XII, pp. 717-733.

Huot, L. y vouvenel, P. 1918: La Psychologie du soldat. Paris: La Rennaissance du livre. KAHN, E. L. 1984: The Neglected Majority: «Les Camoufleurs», Art History, and World War I. Londres: University Press of America.

Liberman, A. 1960: The Artist in his Studio. Londres: Thames\&Hudson.

MARC, F. 1996: Lettres du front. Châtillon: Fourbis, Collection SH.

MARE, A. 1996: Carnets de guerre 1914-1918, présenté par L. Graffin. París: Herscher. MCCABE, L. R. 1918: «Camouflage: War's Handmaid», en The Art World, vol. 3, n. 4, pp. 313-318.

NOUVEAU, R. 1975: «Le camouflage de guerre», en Études touloises, n. 4, fasc. 2, pp. 42-45.

o'mahony, C. 2010: «Cubist Chamaleons: André Mare, the Camoufleurs, and the Canons of Art History's», en Journal of War and Culture Studies, vol. 3, n.1, marzo, pp. 11-35.

PAULHAN, J. 1980: «À propos du camouflage ou la curieuse méprise d'un critique d'art improvisé», Barqueé le patron. París: Gallimard.

PECCATE, Patrick 2015: «Cubisme et camouflage. Un mythe de l'histoire de l'art», Déjà $v u$, en http://dejavu.hypotheses.org/2220 (consultado el 5 de octubre de 2015).

PICASSO/APOLlinaire 2000: Correspondencia (edición de Pierre Caizergues y Hélène Sackel). Madrid: Visor.

PIERREFUE 1920: «La section du camouflage, 1917-18» (L'illustration, n. 4009, 3 enero), 
en André Mare 1998: Cubisme et camouflage, 1914-18. Catalogue de l'exposition présentée au Musée Municipal des Beaux-Arts, du 31 mai au 16 août, Bernay, pp. 27-38.

ROSKAM, A. 1989: «Dazzle painting: arte come camuffamento, camuffamento come arte», en Casabella, vol. 557, pp. 24-26.

SAlmon, A. 1920: «Cubisme et camouflage», en L'art vivant. París: Éditions G. Crès, pp. 159-162.

SCOLARI, M. 1989: «La costruzione dell'invisibile. Occultamento e camouflage nella guerra moderna», en Eidos, Rivista di arti, letteratura e musica, n. 6, pp. 56-78.

Maite Méndez Baiges es Profesora titular de Historia del Arte de la Universidad de Málaga. 
